\title{
Carbon mineralization from sewage sludge-amended mine dump by response surface methodology
}

\author{
A. Sevilla-Perea • M. C. Hernández-Soriano • \\ M. D. Mingorance
}

Received: 12 January 2013/Revised: 27 May 2013/Accepted: 17 November 2013/Published online: 20 December 2013

(C) Islamic Azad University (IAU) 2013

\begin{abstract}
Application of sewage sludge to degraded soil has received considerable attention because of its potential for soil fertilization and also as an effective, low-cost disposal method. An understanding of the decomposition of organic substrates in soil is essential to determine the relative worth of different materials for the improvement of soil agrochemical properties. Therefore, this study was aimed to evaluate the $\mathrm{C}$ mineralization of mining soil amended with dried sewage sludge and co-composted with olive pruning by response surface methodology. We carried out an aerobic incubation in the laboratory using varying doses of waste $\left(0-100 \mathrm{~g} \mathrm{~kg}^{-1}\right)$ following a D-optimal design over 30 days at $40 \%$ field capacity and $28{ }^{\circ} \mathrm{C}$. The $\mathrm{CO}_{2}$ evolution pattern was monitored throughout the incubation time. The experimental design allowed evaluating how the characteristics of the sludge affected the $\mathrm{C}$ mineralization process as showed by surface and contour plots and estimated the kinetic parameter of $\mathrm{CO}_{2}-\mathrm{C}$ production at several application doses. The dried sludge supplied an easily degradable $\mathrm{C}$ pool that produces 5 times higher $\mathrm{CO}_{2}-\mathrm{C}$ than that found for the co-composted one. Mineralization process, performed differently for each sludge, can be discriminated by mineralization and metabolic quotients. Additionally, fluorescence
\end{abstract}

\footnotetext{
A. Sevilla-Perea $\cdot$ M. D. Mingorance $(\square)$

Instituto Andaluz de Ciencias de la Tierra (UGR-CSIC), Avda. de las Palmeras 4, 18100 Armilla,

Granada, Spain

e-mail: mdmingorance@iact.ugr-csic.es

M. C. Hernández-Soriano

Division of Soil and Water Management,

Katholieke Universiteit Leuven, Kasteelpark Arenberg 20,

3001 Heverlee, Belgium
}

spectrometry also discriminates the composition of dissolved organic matter from each substrate. In both cases, soil biological activity was enhanced. The overall results suggest that response surface methodology was effective in the assessment of $\mathrm{C}$ mineralization over a wide range of sludge doses and times, in the identification of interactions between incubation factors and in the prediction of the dose of sludge and time for obtaining target $\mathrm{C}$ mineralization (and vice versa).

Keywords Organic matter - D-optimal design - Mine dump · Dried sludge $\cdot$ Co-compost $\cdot$ Soil respiration . Soil biochemical properties

\section{Introduction}

The main problems of mine waste concern damage to the landscape, acidification of running water and groundwater, and erosion by weathering (Mays et al. 2000), and it has now become imperative for mine waste to be treated and reclaimed by planting. However, mine dumps are an extremely harsh environment for plant growth, and survival of plant species is limited by unfavorable physical, chemical, and biological factors, including sand-blasting effects from sharp-edged wind-eroded particles, drought due to low water-holding capacity, and nutrient impoverishment, as well as occasional high surface temperatures, low $\mathrm{pH}$, and metal toxicity (Sheoran et al. 2010). One of the most important limitations for plant growth is the lack of organic matter (OM) in this type of soils. In the short term, the application of organic amendments may be of assistance (Song and Lee 2010; Marando et al. 2011) by improving the physicochemical and biological properties of the soil and so its natural productivity and fertility (Roig et al. 
2012). The most widely used, efficient, and low-cost organic amendments are sewage sludge and related biosolids, which have high contents of organic matter, $\mathrm{N}$ and $\mathrm{P}$ (Epstein 2003), and are therefore suitable for application at mine sites to establish sustainable vegetation (Song and Lee 2010).

Soil biological activity plays an important role in regulating soil fertility and/or soil sustainability. Several biological parameters such as microbial biomass and $\mathrm{CO}_{2}$ production have been used to define the status and sustainable development of productivity in soils (Mummey et al. 2001; Turrión et al. 2012). Soil respiration, determined as the net heterotrophic production of $\mathrm{CO}_{2}-\mathrm{C}$, results from the mineralization of organic $\mathrm{C}(\mathrm{OC})$, a process in which residence times and $\mathrm{C}$ input play a dominant role (Yuste et al. 2007).

Soil respiration has been shown to correlate strongly with C supply, and linear or nonlinear, single, or multiphase kinetic models have been developed. The first-order model is the most widely applied one even so other approaches based on this simple model with additional parameters related to OM pools of various degrees of stability have been proposed (Fernández et al. 2007; Gillis and Price 2011; Turrión et al. 2012). These models are experimentally derived mathematical equations describing the evolution of soil respiration $\left(\mathrm{CO}_{2}\right.$ produced vs. incubation time), the potentially mineralizable $\mathrm{C}$ fractions, and the $\mathrm{C}$ mineralization rates. These approaches focus on the goodness of fit of the model simulating mineralized $\mathrm{C}$ caused by biological processes, but none of these models explicitly considers amendment dose and takes into account interactions between incubation parameters. These methods are also time-consuming, and several independent sets of respiration experiments are required for reliable assessment of the different amendment dosages. There are advantages to be gained from the use of response surface methodology (RSM), which is an empirical modeling tool useful for analyzing and optimizing the response of multivariate systems (Myers and Montgomery 2002; Khuri and Mukhopadhyay 2010). RSM provides a significant amount of information from a small number of experiments, as well as describing the interaction of independent factors on the responses, especially in biochemical processes where interactions such as synergism and antagonism between factors would be more critical. As a result of the in-depth knowledge on processes gained through RSM, together with the effectiveness of the fitted models for prediction of behavior of the system under particular conditions, in the last few years, RSM has been progressively applied to biochemical and bioenvironmental systems, for example, analysis and modeling of anaerobic digestion processes
(Amani et al. 2011), $\mathrm{Pb}$ adsorption on Aspergillus terreus (Cerino Córdoba et al. 2011), or polluted soil remediation using soil washing with surfactants (Hernández-Soriano et al. 2010; Kalali et al. 2011).

The aim of this research was to evaluate the efficiency of sewage sludge to increase OM in a mine dump through a balanced soil amendment. Response surface methodology was used to evaluate the effect of incubation and several applications of dried and co-composted sludge on $\mathrm{C}$ mineralization. Overall, the ultimate goal is to encourage new experimental approaches in the quest for understanding the mechanisms involved in the turnover of soil OM. The research was carried out in the dump of abandoned iron mine located in Alquife (Granada, Spain) during 2010.

\section{Materials and methods}

\section{Soil}

Soil was sampled from a mine dump in Alquife (Granada, Spain) sited at an elevation of approximately $1,250 \mathrm{~m}$ above sea level. The area in question has a continental Mediterranean climate with $357 \mathrm{~mm}$ mean annual precipitation, mainly concentrated in autumn and winter. Summers are extremely dry because of the overlap of the hot and dry seasons between June and September with maximum temperatures of $35^{\circ} \mathrm{C}$. Winters are cold with frequent frosts and low temperatures close to $0{ }^{\circ} \mathrm{C}$ in January. Daily thermal variation is quite high throughout the year, often reaching $20{ }^{\circ} \mathrm{C}$. The mine dump covers 260 ha and varies in height from 60 to $80 \mathrm{~m}$. Herbaceous plant species and shrubs (average height $25 \mathrm{~cm}$ ) predominate. Some of the species present were Thymus mastichina, T. zygis, Retama sphaerocarpa, Helichrysum stoechas, Dittrichia viscous, and Artemisia sp., although their general appearance was depleted. Five soil subsamples were taken $(0-15 \mathrm{~cm})$ and mixed to give an analytical sample which was then airdried and sieved $(<2 \mathrm{~mm})$. The coarse fraction $>2 \mathrm{~mm}$ represents the $47 \%$ of the original soil sample. This fine fraction was used for incubation assays and for physicochemical characterization following standard methods. The moisture content of soil was measured gravimetrically by drying soil sample at $105{ }^{\circ} \mathrm{C}$ for $24 \mathrm{~h}$.

\section{Sewage sludge}

The sewage sludge was the end product of secondary wastewater treatment processes reflecting the composition of raw wastewater and, therefore, anthropogenic activities in the catchment area. The raw sludge was anaerobically 
digested at $35{ }^{\circ} \mathrm{C}$ for 15 days and partially dewatered by centrifuging to a dry matter content of approximately $20 \%$ in the treatment plant. This dewatered sludge cake, supplied by EMSAGRA SA (Granada, Spain), was additionally air-dried for 1 month to reduce its water content and mitigate odor. This material with $<4 \%$ moisture was sieved to $<2 \mathrm{~mm}$ before use and referred to as dried sludge (SW).

The co-compost (SVC), supplied by Biomasa del Guadalquivir SA (Santa Fé, Granada, Spain), was made up by composting the raw SW and agricultural by-products, especially branches and twigs pruned from olive trees, which are abundantly available nearby. The mixture was maintained in stacks of about 3-4 m high, turning regularly to prevent anaerobic processes at environmental humidity (without artificial moistening) during 4-6 months of maturation. The chemical composition and water content were dependent on the time of pruning, but the fiber and lignin content were consistently high with low raw protein contents (Blázquez et al. 2011). The slow biodegradability of this material is a function of its easily degradable biomolecules (hemicellulose and cellulose) and other slowly degradable components (waxes, lignins, and other polyphenols), which ensure long-lasting soil protection. The material was sieved to $<2 \mathrm{~mm}$ before use.

Waste material was analyzed for $\mathrm{pH}$ and electrical conductivity (EC) in aqueous suspension 1:10 (w:v); total $\mathrm{C}$ and $\mathrm{N}$ by elemental analyzer (TOC); and $\mathrm{OC}$ by a modified Walkey and Black method (Mingorance et al. 2007), and humification index (HIX) of dissolved OC was calculated from fluorescence emission spectra (Zsolnay et al. 1999).

\section{Characterization of dissolved organic matter}

Aliquots of amended and non-amended soils were taken after the incubation period and dried at $105{ }^{\circ} \mathrm{C}$ for $24 \mathrm{~h}$. Dissolved organic matter (DOM) was extracted from the oven-dried soil samples after saturation with MQ water and incubation at $25{ }^{\circ} \mathrm{C}$ for $24 \mathrm{~h}$. The soluble fraction was obtained by centrifugation $(10 \mathrm{~min}$ at $3,000 \mathrm{~g}$ ) of $20-30 \mathrm{~g}$ of saturated soil using the double chamber method (Bufflap and Allen 1995). The double chamber is a centrifuge tube that employs a built-in filter seated on top of the cup, with the soil sample placed on top, and a detachable cup on the bottom for collection of the pore water. After centrifugation, the soil solution samples were immediately filtered through a $0.45-\mu \mathrm{m}$ filter. These solutions were diluted so that absorbance at $254 \mathrm{~nm}$ was below 0.2 prior to the collection of fluorescence spectra (Miller et al. 2010). Fluorescence excitation-emission spectra (EEM) were collected on a Perkin-Elmer LS 50B luminescence spectrometer using sealed quartz cuvettes. The spectrometer used a Xenon excitation source, and slits were set to $5 \mathrm{~nm}$ for both excitation and emission. The excitation wavelengths were increased from 250 to $400 \mathrm{~nm}$ in 5-nm steps for each excitation wavelength, and emission was detected from 250 to $500 \mathrm{~nm}$ in $0.5-\mathrm{nm}$ steps. Blank water scans were run for every 10-15 analyses. The collected spectra were analyzed by FL WinLab 4.00 .03 (PerkinElmer Inc., 2006).

\section{Soil mineralization of organic C}

Organic $\mathrm{C}$ mineralization $\left(\mathrm{C}_{\mathrm{min}}\right)$ was determined by the measurement of soil $\mathrm{CO}_{2}$ respiration. Sludge was added to soils at $33,50,67$, and $100 \mathrm{~g} \mathrm{~kg}^{-1}$, according to the experimental matrix of the D-optimal design, and thoroughly mixed. Incubation assays were carried out using untreated soil (s) and soil amended with SW (s + SW) and SVC (s + SVC). Samples of $50 \mathrm{~g}$ dried soil $(2.3 \%$, natural moisture content) were weighed into $50-\mathrm{mL}$ plastic beakers in duplicate and mixed with the doses of each sludge. Each mixture was wetted to $40 \%$ field capacity and placed in 1-L air-tight containers with alkali traps containing $20 \mathrm{~mL}$ of $0.5 \mathrm{M} \mathrm{NaOH}$ to avoid $\mathrm{CO}_{2}$ loss or entry. The samples were incubated at $25^{\circ} \mathrm{C}$ for 4 weeks. Moisture losses were controlled and corrected during incubation. The alkali traps were replaced regularly depending on $\mathrm{CO}_{2}$ production. This was necessary every day for the first 10 days, and then after 15,21 , and 30 days. $\mathrm{CO}_{2}$ production was measured by titration. The alkali reacts chemically with $\mathrm{CO}_{2}$ and $\mathrm{BaCl}_{2}$ $1 \mathrm{M}$ and can be back-titrated with hydrochloric acid $(\mathrm{HCl}$ $0.25 \mathrm{~N}$ ) to a phenolphthalein endpoint relative to the amount of $\mathrm{CO}_{2}$ released by soil microorganisms (Anderson 1982). Three control vials with no soil were included in the incubation to correct for $\mathrm{CO}_{2}$ in the container at the start of the incubation period. Mineralized $\mathrm{C}$ was expressed as $\mathrm{mg}$ $\mathrm{CO}_{2}-\mathrm{C}$ per $\mathrm{kg}$ soil.

Amended soil samples were collected for analysis after incubation. Electrical conductivity and $\mathrm{pH}$ were measured in 1:2.5 (w:v) soil suspension. Microbial biomass C $\left(\mathrm{C}_{\text {biom }}\right)$ was determined by the chloroform fumigationextraction (CFE) method (Vance et al. 1987). The filtered extracts $\left(0.5 \mathrm{M} \mathrm{K}_{2} \mathrm{SO}_{4}\right)$ of both fumigated and nonfumigated samples were analyzed for soluble organic $\mathrm{C}$ using a TOC analyzer (Shimadzu TOC-5000A). Microbial biomass $\mathrm{C}$ was estimated as the difference in organic $\mathrm{C}$ extracted from the fumigated and non-fumigated samples, multiplied by the $\mathrm{K}_{2} \mathrm{SO}_{4}$ extract efficiency factor for microbial $\mathrm{C}\left(k_{\mathrm{c}}=2.64\right)$. Enzyme activity of $\beta$-glucosidase (Glu) was also determined following Eivazi and Tabatabai (1988). All results are expressed as oven-dried matter at $105{ }^{\circ} \mathrm{C}$. 
Experimental design

The term response surface methodology (RSM) is originated from the graphic representation generated by fitness of a mathematical model, and its use has been widely adopted in the field of chemometrics. RSM consists of a group of mathematical and statistical techniques based on the fit of empirical models to the experimental data obtained from experimental design. With this aim, polynomial functions are used to describe the system studied and, subsequently, to explore (modeling) experimental conditions, to predict the behavior of the system under experimental conditions, and/or to optimize the experimental conditions to achieve target values of the response. Before applying RSM, a design of experiment was first required to select the points where the response should be evaluated, i.e., which experiments should be carried out in the experimental region being studied. For this study, we chose a design of experiment determined by the D-optimality criterion described elsewhere (Myers and Montgomery 2002; Delgado Moreno et al. 2009). The D-optimality criterion enables a more efficient construction of a quadratic model (Myers and Montgomery 2002). Its objective is to select a number of design points from a larger set of candidate points. In short, this criterion states that the best set of points in the experiment maximizes $\left|X^{\prime} X\right|$, the determinant of the information matrix $X^{\prime} X$ of the design, which is equivalent to minimize the variances in the estimated coefficients of the response model, where $X$ is the model matrix with dimensions $\mathrm{Nxp}$ ( $\mathrm{N}$ the number of experiments and $P$ the number of model coefficients). From a statistical point of view, a D-optimal design leads to response surface models for which the maximum variance of the predicted responses is minimized. Also, this design is more flexible than classical ones (factorial, central composite, etc.) and may therefore better adapt to those cases where any combination of values in the experimental variables is not possible (the experimental region is not regular in shape), the number of experiments is limited, and there is the possibility to include extra design points.

The D-optimal design was made for each amendment by taking into account two main experimental factors involved in the reclamation of mine dump: the amendment application rate $(D)$ and the incubation time $(t)$. Doses ranged from none (non-amended, $D=0$ ) to a value higher than the environmentally sound dose $\left(D=100 \mathrm{~g} \mathrm{~kg}^{-1}\right)$. The highest dose was determined according to European guidelines (ED 86/278/EEC 1986) to ensure that no heavy metals in the amended soil exceeded the limit values as a result of the application of sludge. However, the highest dose exceeded the limit values for concentrations of heavy metals introduced in soil annually with sludge application, based on 10-year average. Nevertheless, this directive is currently applicable only for soils supporting agricultural activities. Therefore, the dose of $100 \mathrm{mg} \mathrm{kg}^{-1}$ can still be considered environment friendly, considering that the restored mine dump is not intended for agricultural use. Incubation time $(t)$, which represents the time between sludge application and vegetation setup, ranged from 1 to 30 days. The $\mathrm{CO}_{2}$ releases and mineralization quotient, indicators of the mineralization process, were chosen as responses to be evaluated. The D-optimal design was setup, and data analysis was performed using Design-Expert 7.1.3 (Stat-Ease, Inc., USA). The design consisted of 12 experiments: four extreme vertices, four edge points, and four central points giving a G-efficiency of $74 \%$. The G-efficiency value is a measure of the statistical performance of the design in relation to that of a fractional factorial design (for which G-efficiency $=100 \%$ ), and a value above 65-70 \% has been recommended (Eriksson et al. 1998). Experiments were performed in random order to minimize the effects of uncontrolled variables that may introduce bias into the measurements.

The accumulated evolved $\mathrm{CO}_{2}-\mathrm{C}$ and mineralization quotient (qM) were fitted to second-order polynomial models (Eq. 1):

$Y=b_{0}+b_{D} x_{D}+b_{t} x_{t}+b_{D * D} x_{D}^{2}+b_{t * t} x_{t}^{2}+b_{\mathrm{Dxt}} x_{D} x_{t}$

where $Y$ is the response to be modeled, $b_{i}$ are the regression coefficients, and $x_{i}$ represent experimental factors.

The goodness of fit was evaluated by $R^{2}$ and $Q^{2}$, and by several diagnostic tools such as the Box-Cox plot for power transformations, normal probability plot of the residuals (N-plot), and studentized residuals to check for normality of residuals and to detect outliers (Hernández-Soriano et al. 2007). ANOVA was performed to measure which model terms contribute significantly to the variance of the responses. When the $P$ value is lower than 0.05 , the term has a statistically significant effect. Contour plots were obtained from the regression equation in actual levels of variables, keeping the response function on the $\mathrm{Z}$ axis with $X$ and $Y$ axes representing the independent variables (Myers and Montgomery 2002). Finally, the validity of the model, i.e., the ability of the model to predict, was evaluated by regression analysis between experimental values and estimated values predicted by the model for ten verification experiments. These experiments consist of additional measurement of $\mathrm{CO}_{2}-\mathrm{C}$ from the incubation of mixtures for times and doses other than those included in the D-optimal design. 
Statistical analysis

Exploratory analysis was carried out to check for normality of the data sets. Differences in treatments were determined by ANOVA of normal data sets and Kruskal-Wallis test of non-normal data sets. Otherwise, the post hoc Tukey test was used to compare several means. Comparison between two sample means was performed by the $t$ test or MannWhitney test. Relationships between variables were assessed by either correlation analysis or regression analysis. Exploratory factor analysis based on principal components analysis (PCA) was performed on the whole soil analytical data in order to find out similarities and correlations among properties and to recognize groups of samples with similar behavior. The plot of loadings (weights of original variables on the linear combination) for principal components was obtained for visual representation.

Model parameters of zero-order and first-order exponential equations (Fernández et al. 2007) fitted for each treatment were calculated by nonlinear regression analysis with the Marquardt-Levenberg algorithm (Rovira and Rovira 2010). This algorithm estimates values of model parameters by minimizing the sum-of-squares error function.

Values for $P<0.05$ were considered significant. SPSS v.17.0 (Illinois, USA) was used for statistical data analysis.

Biological indices, considered as potential indicators of soil biological properties and processes, were calculated as follows:

- Soil basal respiration (SBR): Difference between $\mathrm{CO}_{2}$ $\mathrm{C}$ evolved ( $\left.\mathrm{mg} \mathrm{kg}^{-1}\right)$ at 30 and 7 days

- Mineralized C $\left(\mathrm{C}_{\text {min }}\right)$ : Cumulated $\mathrm{CO}_{2}\left(\mathrm{C} \mathrm{mg} \mathrm{kg}^{-1}\right)$ evolution after 30 days

- Microbial biomass $\mathrm{C}\left(\mathrm{C}_{\text {biom }}\right)$ : Microbial biomass $\mathrm{C}$ $\left(\mathrm{mg} \mathrm{kg}^{-1}\right)$

- Microbial quotient: $\mathrm{C}_{\text {biom }} * 100 / \mathrm{OC}$

- Daily metabolic quotient $\left(\mathrm{qCO}_{2}\right)$ : daily $\mathrm{C}_{\min }$ divided by $\mathrm{C}_{\text {biom }}$

- Mineralization quotient (qM): $\mathrm{C}_{\min } * 100 / \mathrm{OC}$

\section{Results and discussion}

Physicochemical properties of the soil and organic amendments

According to the FAO-UNESCO soil classification system, the soil was a Technosol containing $42 \%$ of coarse fragments $(>2 \mathrm{~mm})$. The bulk density $\left(1.66 \mathrm{~g} \mathrm{~cm}^{-3}\right)$ indicated high compaction; the field
Table 1 Sewage sludge properties: dried (SW) and composted with olive prune wastes (SVC)

\begin{tabular}{llllllll}
\hline & $\mathrm{EC} \mathrm{dS} \mathrm{m}^{-1}$ & $\mathrm{pH}$ & $\mathrm{OC} \%$ & $\mathrm{C}_{\text {total }} \%$ & $\mathrm{~N} \%$ & $\mathrm{C} / \mathrm{N}$ & $\mathrm{HIX}$ \\
\hline $\mathrm{SW}$ & 3.5 & 6.8 & 32 & 35 & 6.0 & 5.4 & 0.43 \\
$\mathrm{SVC}$ & 1.5 & 7.3 & 19 & 21 & 2.6 & 7.5 & 2.2 \\
\hline
\end{tabular}

$E C$ electrical conductivity, $O C$ organic $\mathrm{C}, H I X$ humification index defined as fluorescence intensity in the $435-480 \mathrm{~nm}$ region divided by the intensity in the $300-345 \mathrm{~nm}$ region

capacity (19\% (v/v), $0.03 \mathrm{MPa})$ showed low water retention, and the infiltration rate $\left(25 \mathrm{~mm} \mathrm{~h}^{-1}\right)$ was high according to the texture.

Mineralogical analysis showed that $80 \%$ of the soil consists of $\mathrm{Fe}$ oxides, calcite and $\mathrm{SiO}_{2}$, and traces of clays. The $\mathrm{Fe}$ oxides extracted with dithionite were of $2.3 \%$, mainly as a result of the $\mathrm{Fe}$ mineral treatment activities. The soil had a moisture content of $2.3 \%$ and an alkaline pH (8.2) with low EC $\left(0.055 \mathrm{dS} \mathrm{m}^{-1}\right)$. From an agrochemical standpoint, it is low in organic $\mathrm{C}$ content $(0.18 \%)$, suggesting a low capacity to produce biomass, retain water, and give structure to the soil; the low cation exchange capacity $\left(<3 \mathrm{cmol}_{+} \mathrm{kg}^{-1}\right)$ shows that the soil has low nutrient storage capacity, as well as a reduced nutrient availability for plants and low total $\mathrm{N}(0.06 \%)$ and available $\mathrm{P}\left(\mathrm{P}_{\text {olsen }} 7.8 \mathrm{mg} \mathrm{kg}^{-1}\right)$.

The composition of the amendments was summarized in Table 1. The $\mathrm{pH}$ was similar for both, but EC was twice as high for SW. The OC content was higher for SW and also differed regarding quality of $\mathrm{OM}$ and $\mathrm{N}$ availability. Values of HIX were lower for SW than for SVC, in accordance with its less humified OM. The low $\mathrm{C} / \mathrm{N}$ relationships indicated that both residues are an important source of $\mathrm{N}$ for the aerobic microorganisms responsible for mineralization. On the other hand, the potential toxic metal concentrations of both sludges (data not shown) were much lower than those stipulated for external applications to soil by ED 86/278/EEC (1986).

\section{Carbon mineralization}

Soil-accumulated $\mathrm{CO}_{2}-\mathrm{C}$ was assessed by RSM as a function of both waste dosage and incubation time after application of each sludge. The experimental plan was carried out according to the D-optimal design. The amount of mineralized $\mathrm{C}\left(\mathrm{mg} \mathrm{kg}^{-1}\right)$ was fitted to a square polynomial equation by partial least squares (Table 2 ). The $\mathrm{R}^{2}$ values indicated that the model explained $\geq 99 \%$ of the experimental variability found for the response, without lack of fit $(P>0.05)$, and the prediction coefficients $\left(Q^{2}>0.5\right)$ indicated a good predictive ability for the model 
Table 2 Orthogonal PLS coefficients regression (standard error) and goodness-of-fit indicators for measured parameters

\begin{tabular}{|c|c|c|c|c|}
\hline & \multicolumn{2}{|c|}{$\mathrm{CO}_{2}-\mathrm{C} \mathrm{mg} \mathrm{kg}{ }^{-1}$} & \multicolumn{2}{|l|}{$\mathrm{qM} \%$} \\
\hline & SVC & SW & SVC & SW \\
\hline Constant & $603(23)$ & 2,713 (109) & $5.2(0.2)$ & $14(1.0)$ \\
\hline$D$ & $341(31)$ & 1,791 (96) & $-0.50(0.2)$ & $3.4(0.9)$ \\
\hline$t$ & 357 (20) & 1,778 (96) & $3.1(0.2)$ & $7.2(0.9)$ \\
\hline$D^{2}$ & $P>0.05$ & $-482(155)$ & $P>0.05$ & $6.7(1.0)$ \\
\hline$t^{2}$ & $-208(31)$ & $-517(155)$ & $-1.5(0.3)$ & $P>0.05$ \\
\hline Dxt & 305 (24) & $1,630(113)$ & $P>0.05$ & $3.1(1.0)$ \\
\hline$R^{2}$ & 0.993 & 0.995 & 0.978 & 0.984 \\
\hline$Q^{2}$ & 0.985 & 0.974 & 0.959 & 0.907 \\
\hline $\mathrm{LoF}$ & 0.923 & 0.427 & 0.842 & 0.529 \\
\hline RSD & 49 & 197 & 0.45 & 1.2 \\
\hline
\end{tabular}

$D$ is the dose, $t$ the incubation time, $R^{2}$ the determination coefficient, $Q^{2}$ the prediction coefficient, $L o F$ the lack of fit, $R S D$ the residual standard deviation, $P L S$ partial least squares, $q M$ mineralization quotient

(Lundstedt et al. 1998). The assumptions of normality and constant variance of the residuals were satisfied for the fitted model as shown by diagnostic plots such as the normal probability plot of residuals and a plot of residuals versus predicted values (data not shown). Table 2 summarizes the significant regression coefficients $(P<0.05)$ of the model, together with the statistical data obtained from ANOVA. The contribution of $D$ and $t$ to the $\mathrm{CO}_{2}$ released is shared (each explained about $30 \%$ total variance) for both amendments, the contributions of Dxt effects were $18 \%$, and the quadratic effects were low $(<10 \%)$. Surface response plots (Fig. 1a, c) illustrate how the $\mathrm{CO}_{2}$ release is affected by $D$ and $t$ inside the experimental region, and the contour line represents the experimental conditions under which the same $\mathrm{CO}_{2}$ production is obtained. Due to the significant Dxt interaction, every amendment dose shows a specific pattern along the incubation. In case of s + SVC (Fig. 1a), the highest mineralization of the substrate occurs when a dose $>85 \mathrm{~g} \mathrm{~kg}^{-1}$ was applied and after three incubation weeks, but ca. $43 \%$ of $\mathrm{C}$ was mineralized during the first incubation week. In case of $\mathrm{s}+\mathrm{SW}$ (Fig. $1 \mathrm{c}$ ), the highest mineralization of SW occurs when a dose $>80 \mathrm{~g} \mathrm{~kg}^{-1}$ was applied and after 24 incubation days, whereas lower mineralization corresponded to a dose $<20 \mathrm{~g} \mathrm{~kg}^{-1}$ occurs during the first 10 incubation days. Overall, both sludge show a different behavior during the first incubation weeks, but the $\mathrm{CO}_{2}-\mathrm{C}$ production for the addition of soil with SW was fivefold higher compared to application of SVC. The validity of the model was confirmed by comparing experimental $\mathrm{CO}_{2}-\mathrm{C}$ values with those predicted by the model equations (Fig. 2). We obtained a statistically significant overall linear regression $\left(R^{2}=0.988 ; P<0.001\right)$, with an intercept statistically equal to zero $(P=0.383)$ and a slope close to $1(0.98 \pm 0.26)$, which indicated that the predicted and measured evolved $\mathrm{CO}_{2}-\mathrm{C}$ was not statistically different.

Furthermore, the model fitted can predict the curve of $\mathrm{CO}_{2}-\mathrm{C}$ released from soil after amending inside the experimental field. For example, Fig. 3 shows the evolution of released $\mathrm{CO}_{2}$ after several doses of amendments (10-150 $\mathrm{g} \mathrm{kg}^{-1}$ ) were added over a short period. The firstorder equation $C_{t}=C_{0}\left(1-e^{-\mathrm{kt}}\right)$ provides a good description of the $\mathrm{C}$ mineralization kinetics and $R^{2}$ values ranged from 0.956 to 0.999 for the two types of sludge. However, there are two exceptions: When $<10 \mathrm{~g} \mathrm{~kg}^{-1}$ doses were added, a good fit was found for a shorter incubation period (20 days) in both cases, and, in the case of $\mathrm{s}+\mathrm{SW}$ at $150 \mathrm{~g} \mathrm{~kg}^{-1}$, the zero-order model $\left(C_{t}=286^{*} t\right)$ achieved the best fit for $\mathrm{CO}_{2}-\mathrm{C}$ data. A higher mineralization rate occurred in $\mathrm{s}+\mathrm{SW}$ $\left(0.27-0.67\right.$ days $\left.^{-1}\right)$ than in $\mathrm{s}+\operatorname{SVC}\left(0.43-0.96\right.$ days $\left.^{-1}\right)$. The potentially mineralizable $\mathrm{C}$ pool $\left(C_{0}\right)$ had a high linear relation to the $\mathrm{C}$ inputs from $\operatorname{SVC}\left(R^{2}=0.971, P<0.001\right)$ and SW $\left(R^{2}=0.964, P<0.001\right)$. The initial potential rate of $\mathrm{C}$ mineralization normalized to total $\mathrm{C}\left(C_{0} * k / \mathrm{C}_{\text {total }}\right)$ was higher for SW than for SVC (Fig. 3).

\section{Carbon mineralization index}

The qM values were also fitted to a square polynomial equation, and indicators of the goodness-of-fit and significant regression coefficients of the model are shown in Table 2. The contribution of $\mathrm{t}$ in $\mathrm{qM}$ is dominant (accounting for $87 \%$ ), and contributions of quadratics and interaction effects were low $(<10 \%)$.

Contour plots (Fig. 1) show that the addition of SW provided a qM up to $22 \%$ at doses $50-90 \mathrm{~g} \mathrm{~kg}^{-1}$ after 27 incubation days, whereas for SVC up to qM $7 \%$ is reached at a dose $<15 \mathrm{~g} \mathrm{~kg}^{-1}$ and $t>25$ days. The significant Dxt interaction when $\mathrm{SW}$ is added produced a strong curvature of the isolines (Fig. 1d) so that doses $<35 \mathrm{~g} \mathrm{~kg}^{-1}$ incubated along 30 days showed $\mathrm{qM}$ $\left(8.2 \%\right.$ ) similarly to doses $>63 \mathrm{~g} \mathrm{~kg}^{-1}$ incubated along 11 days. In case of $\mathrm{s}+\mathrm{SVC}$ (Fig. 1b), significant Dxt interaction gave two different $\mathrm{qM}$ behavior depending on the incubation times. For $t<21$ days, the SVC dose applied produced slightly linear increases in $\mathrm{qM}$, whereas at $t>21$ days, higher $\mathrm{qM}$ is found when soil is amended with a lower SVC dose. 


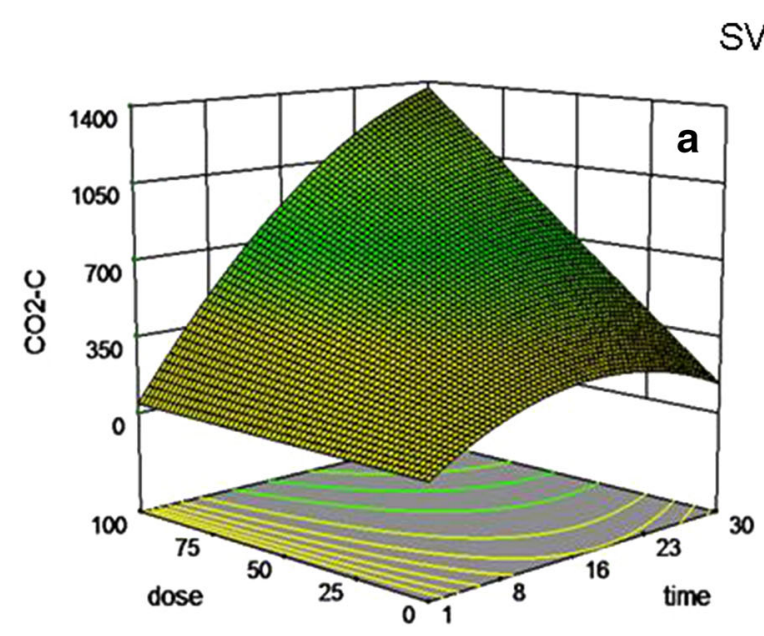

SVC
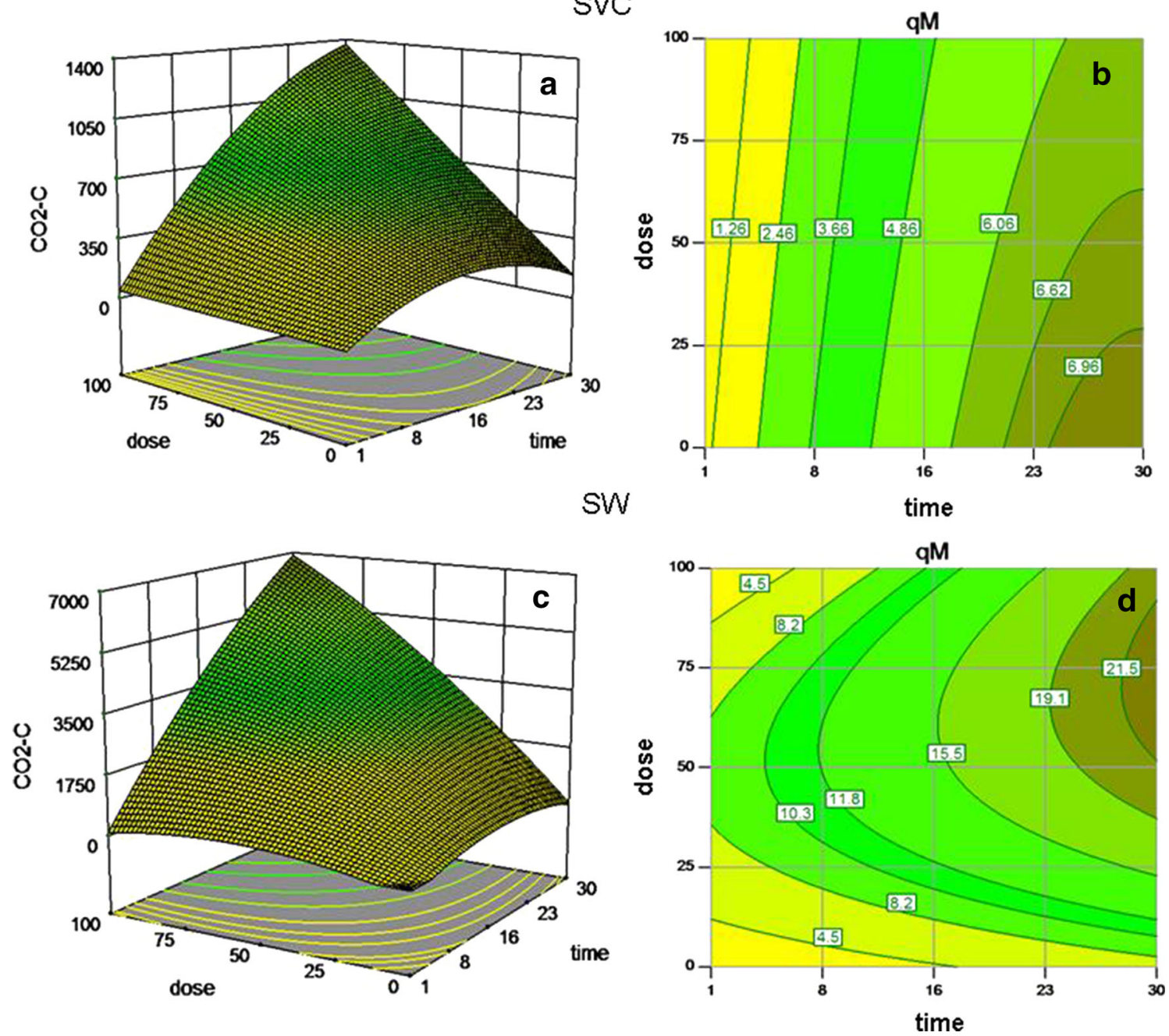

Fig. 1 Surface plots $(\mathbf{a}, \mathbf{c})$ showing the effect of dried (SW) and composted (SVC) sewage dosage and incubation time on $\mathrm{CO}_{2}$ release $\left(\mathrm{mg} \mathrm{kg}^{-1}\right)$. Contour plots $(\mathbf{b}, \mathbf{d})$ for mineralization quotient (qM, \%).

The colour change from yellow to dark green corresponds to increase in response

Assessment of soil biochemical properties at the end of incubation

Effects of dose and characteristics of both organic substrates on several chemical and biological parameters were determined. The amount of $\mathrm{C}$ added to soil is 1.6 times lower and more stabilized with SVC than with SW, resulting in 5 times lower amounts of stable organic $\mathrm{C}$.

Among soil chemical properties, $\mathrm{pH}$ was not significantly affected by the addition of SW $(P>0.05)$, but the addition of SVC significantly lowered $(P<0.05)$ soil $\mathrm{pH}$ (7.7) compared to control soil (8.4) regardless of the dose applied. All waste dosages increased the EC of the soil, with the highest values found with the addition of SW. EC

values were similar $(P>0.05)$ at 33,50 , and $67 \mathrm{~g} \mathrm{~kg}^{-1}$ doses of SW, but they were significantly lower than when SW was applied at $100 \mathrm{~g} \mathrm{~kg}^{-1}(P=0.010)$. For the addition of SVC, EC values were in direct relation to the doses applied $\left(R^{2}=0.979 ; \mathrm{EC}=292+5.5^{*} D\right)$.

In relation to soil biochemical properties, Glu activity was consistently related to the waste dose applied for both SW and SVC, although significantly higher values $(P<0.05)$ were obtained with the application of SW (SVC: $R^{2}=0.912 ; \quad$ Glu $=0.25^{*} D ; \quad$ SW: $R^{2}=0.987$; Glu $\left.=2.6^{*} D\right)$. The $\mathrm{C}_{\text {biom }}$ increased exponentially with the applied dose regardless of the type of waste (SVC: $R^{2}=0.935 ; \quad \mathrm{C}_{\text {biom }}=44 e^{0.25^{*} D} ; \quad \mathrm{SW}: \quad R^{2}=0.928 ;$ $\mathrm{C}_{\mathrm{biom}}=45 e^{0.29^{*} D}$ ). The $\mathrm{SBR}$ values were higher for soil 


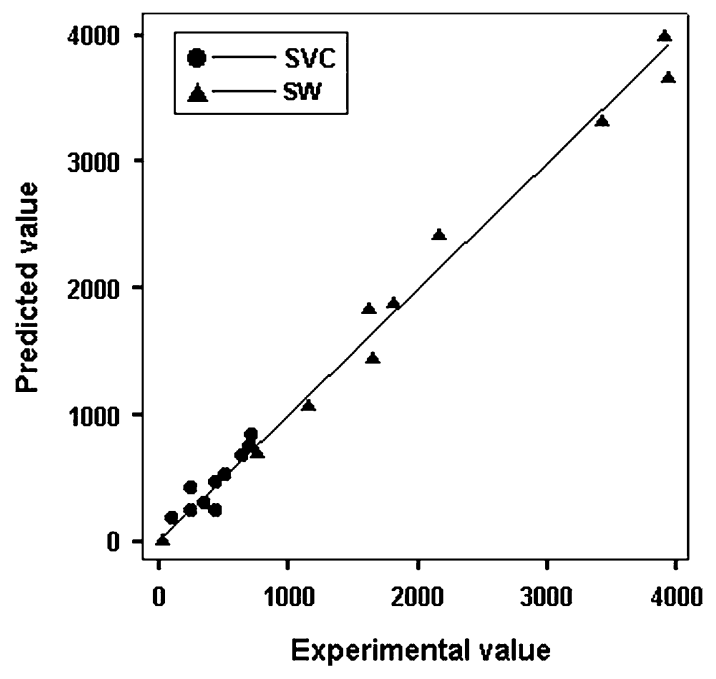

Fig. 2 Parity plot for experimental versus predicted values for mineralized $\mathrm{C}$, expressed as $\mathrm{mg} \mathrm{kg}^{-1}$ of $\mathrm{CO}_{2}-\mathrm{C}$, for mine dump amended with dried (SW) and co-composted (SVC) sewage sludge

amended with SW and proportional to the dose applied $\left(\mathrm{SVC}: \quad R^{2}=0.961 ; \quad \mathrm{SBR}=30^{*} D ; \quad \mathrm{SW}: \quad R^{2}=0.987\right.$; $\operatorname{SBR}=207 * D)$.

The evaluation of the metabolic quotient $\mathrm{qCO}_{2}$ resulted in higher values for the $\mathrm{SW}$-amended soil $(0.54 \pm 0.12 ; P=0.006)$ than for native soil $(0.13$ $\pm 0.05)$, but no significant differences were found for SVC-amended soil $(0.14 \pm 0.04 ; P=0.617)$. The same was observed for $\mathrm{qM}$, where a significant difference resulted between control soil $(7.67 \pm 0.58)$ and soils amended with SW $(21.1 \pm 0.6 ; P<0.001)$. However, the control soil did not differ $(P=0.242)$ from the soil amended with SVC at any dose of waste applied, with an average value of $6.78 \pm 0.48$. Moreover, the microbial quotient for non-amended soil $(1.94 \pm 0.85)$ did not differ from the values obtained for amended soils $(1.77 \pm 0.55 ; P=0.173)$.
Finally, principal component analysis (PCA) was applied to whole data matrix providing that two principal components explained $90 \%$ of data variance, within PC1 (47\% of the variance) $\mathrm{qM}(0.939)$ is strongly related to $\mathrm{qCO}_{2}(0.953)$ and less related to $\mathrm{pH}(0.759)$ and Glu activity (0.702). On the other hand, PC2 (account for $43 \%$ of explained data variance) is related to $\mathrm{C}_{\mathrm{biom}}(0.951)$, soil OC (0.932), EC (0.756), and SBR (0.740). In Fig. 4, the loadings plot of the two components shows that properties included in PC1 are able to separate s $+\mathrm{SW}$ from nonamended and s + SVC, whereas PC2 clearly separates the soil amended with each sludge at the highest dose, i.e., $100 \mathrm{~g} \mathrm{~kg}^{-1}$. This analysis confirms the differences observed between soil amended with both wastes at $100 \mathrm{~g} \mathrm{~kg}^{-1}$ and application of lower doses, as well as the similarity between native soil and soil applied with low doses of SVC.

Fingerprinting of water-soluble organic matter

Excitation(Ex)-emission(Em) revealed significant variations in common pools, the components of DOC (Zhou et al. 2013) for the different treatments assayed (Fig. 5). Thus, for non-amended soil, the main fluorophore identified can be related to the reduced humic substances, i.e., oldest and chemically stabilized organic matter in soil. For soil amended with $\mathrm{SW}$ at $50 \mathrm{~g} \mathrm{~kg}^{-1}$, oxidized humic substances were identified $(\mathrm{Ex} / \mathrm{Em}<250 / 350-500)$ that have been associated with aliphatic $\mathrm{C}$ content (Fellman et al. 2010), but this component was not observed for the higher dose of SW. A tryptophan-like component (Ex/ Em: 275/330-370) was identified in soil amended with SW at 50 and $100 \mathrm{~g} \mathrm{~kg}^{-1}$, commonly related to the presence of highly labile, less-degraded OM (Zhou et al. 2013). For the highest dose of SW, an additional fluorophore (Ex/Em 350/400-500) was observed that could not be related to any of the components currently
Fig. 3 Simulated $\mathrm{CO}_{2}-\mathrm{C}$ evolution from mine soil amended with dried (SW) and composted sewage sludge (SVC) at several doses, including initial potential rate of C mineralization obtained by first-order exponential model. For $150 \mathrm{~g} \mathrm{~kg}^{-1}$ of SW addition, the latter index is not available because zero-order model was fitted. For 5 and $10 \mathrm{~g} \mathrm{~kg}^{-1}$, first-order exponential model was fitted for 20 days
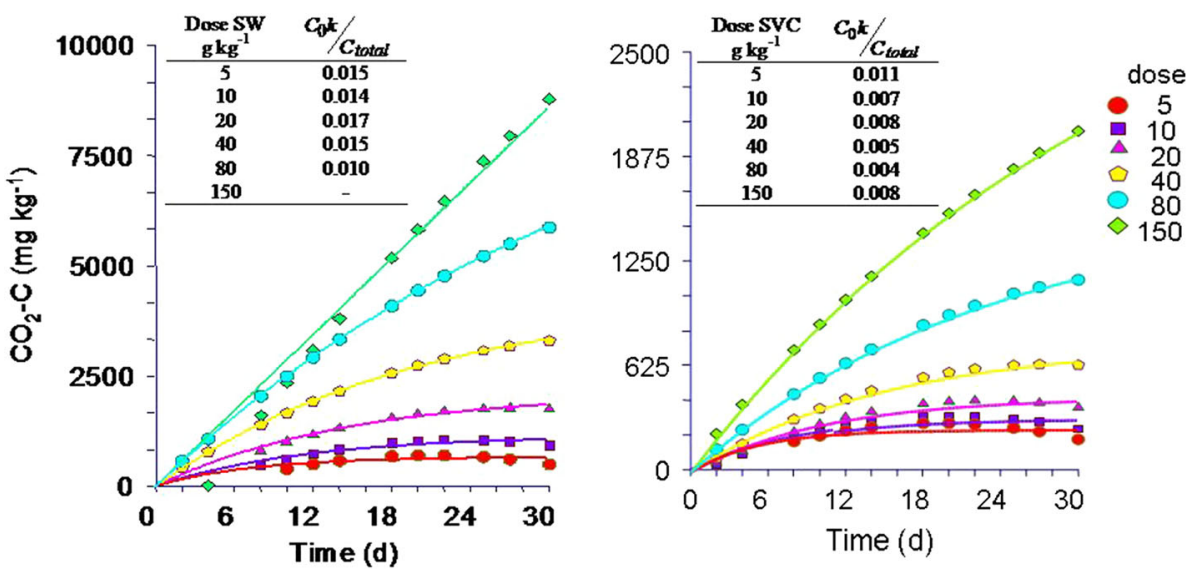


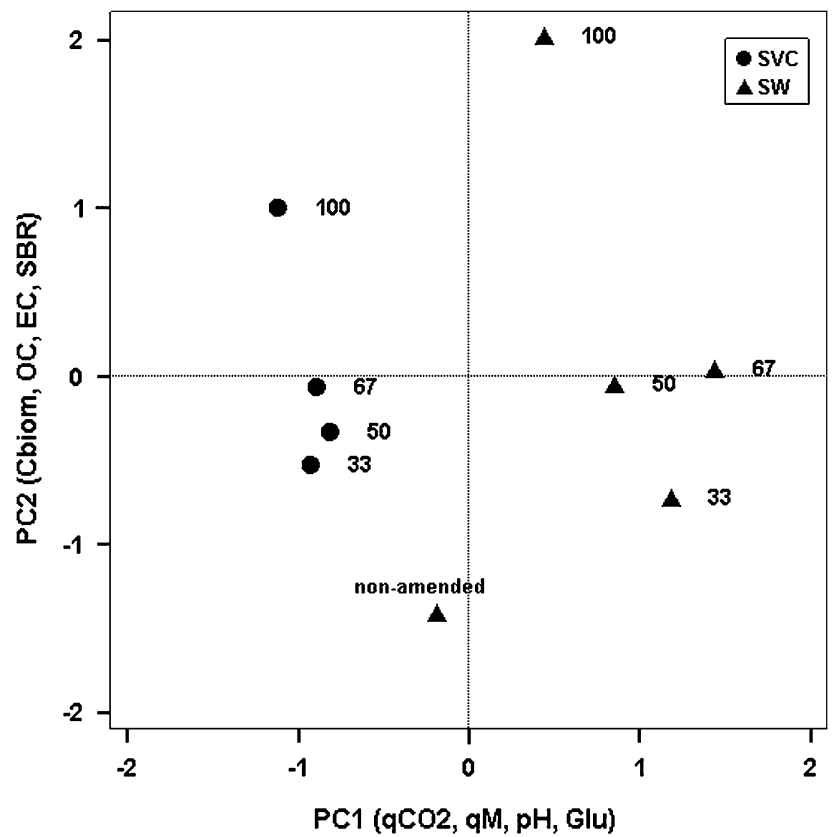

Fig. 4 Loading plot from PCA of all data set containing soil chemical, biochemical, and mineralization index of amended and non-amended soils. Variables given in parenthesis are the ones correlated with each principal component (PC). SBR soil basal respiration, $C_{\min }$ mineralized $\mathrm{C}, C_{\text {biom }}$ microbial biomass $\mathrm{C}, q \mathrm{CO}_{2}$ metabolic quotient, $q M$ mineralization quotient, $E C$ electrical conductivity, Glu glucosidase activity described in the literature. Finally, for soil amended with SVC at 50 and $100 \mathrm{~g} \mathrm{~kg}^{-1}$, a single fluorophore with two excitation peaks at about 250 and $340 \mathrm{~nm}$ (maximum emission around $420 \mathrm{~nm}$ ) was observed, which has been attributed to reduced humic-like compounds (Fellman et al. 2010) with no substantial dose effect was observed. Several indexes derived from the spectrofluorimetric analysis were calculated: HIX, freshness index $\beta: \alpha$, and fluorescence index (FI) (see table in Fig. 5). A decrease in HIX and $\beta: \alpha$ resulted in amended soil after addition of both wastes but not proportionally to the dose applied. It is noted that the HIX decreased up to $88 \%$ at $100 \mathrm{~g} \mathrm{~kg}^{-1}$ compared to non-amended soil. Alternatively, FI slightly increased in amended soil compared to nonamended, whereas it decreased with the increasing dose. The highest FI was reached at $50 \mathrm{~g} \mathrm{~kg}^{-1}$ for both amendments.

The physical properties of the mine dump result in a hostile environment for the development of roots and microbial biomass. The quality indicators for soil agrochemical standpoint also confirmed a low capacity for biomass production, water retention, nutrient storage, and availability for plants as well as an inadequate soil structure. The low $\mathrm{C}$ and $\mathrm{N}$ contents mean that the microorganisms whose activity increases because of $\mathrm{C}$ addition

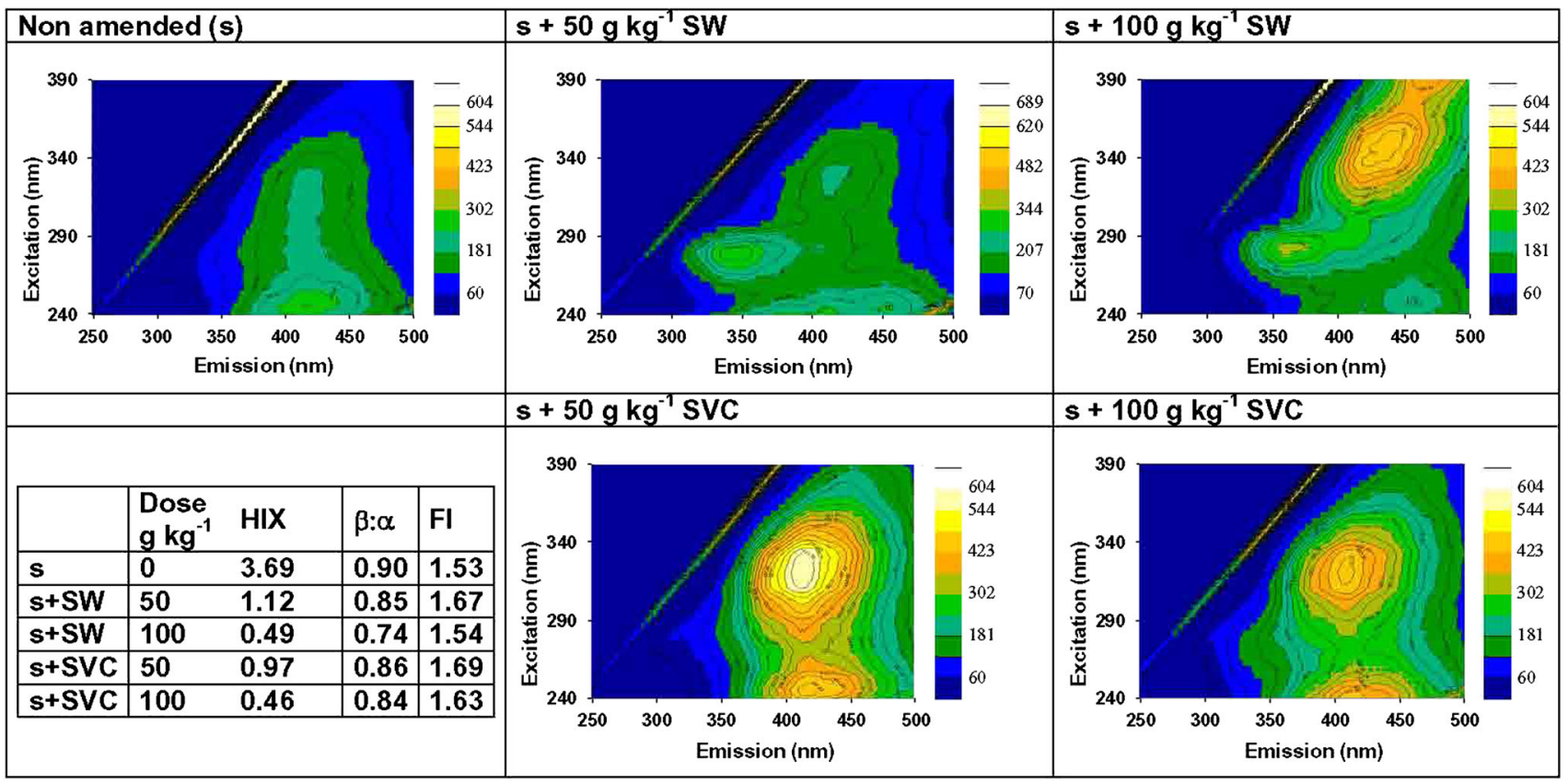

Fig. 5 Excitation-Emission fluorescence spectra of water-extractable organic matter from native soil (s) and amended with dried (SW) and composted (SVC) sewage sludge. Application doses are indicated for each amendment. Humification index (HIX), freshness index $(\beta: \alpha)$, and fluorescence index (FI) were derived from the spectroscopic analysis 
will not obtain enough $\mathrm{N}$. Consequently, the microbes will absorb the plant-available sources of $\mathrm{N}$ in the soil, which would probably cause $\mathrm{N}$ deficiency in plants. Since it is known that without adequate levels of soil OM, the soil was not able to function optimally, current guidance recommends the addition of organic substrates to provide the soil with functional capacity.

The proposed amendments constitute an important source of $\mathrm{C}$ and $\mathrm{N}$ for the aerobic microorganisms responsible for $\mathrm{C}$ mineralization processes, mainly dried $\mathrm{SW}$ that contained high $\mathrm{OC}$ levels with low $\mathrm{C} / \mathrm{N}$ ratio.

Carbon mineralization from sludge amendments

The use of RSM represented a great advantage since it is an empirical modeling tool for developing, improving, and optimizing complex experimental problems as soil $\mathrm{C}$ mineralization process. Experience shows that design of experiments requires fewer experiments than any other approach reducing the time required to perform incubation assays. Twelve experimental runs were required for the evaluation of each amendment applied at doses ranging from 0 to $100 \mathrm{~g} \mathrm{~kg}^{-1}$ in order to model the response, while 30 days of incubation were sufficient to obtain an adequate model. Classical methods require running at least 40 experiments ( 2 amendment $\times 2$ doses $\times 10$ times $)$. The suitability of the model assayed to predict $\mathrm{C}$ mineralization (accuracy of the model) was confirmed by the goodness of the prediction capacity of the model (Fig. 2). In addition, RSM assesses the relationships between $\mathrm{CO}_{2}-\mathrm{C}$ production and the experimental variables $D$ and $t$ detecting both main and interaction effects in the substrate mineralization process (Table 2).

The most significant differences regarding the effects of dose and incubation on the two sludges occur at low doses and/or over short incubation periods (Fig. 1a and c). Mineralization then settles down, and the trends become similar, although still with higher $\mathrm{CO}_{2}-\mathrm{C}$ production in $\mathrm{s}+\mathrm{SW}$ than in soil added with co-composted sludge. During the first week of incubation of $s+S V C$, it seems that the $\mathrm{C}$ fraction of the soil is mineralized possibly because of humified OC from SVC. In case of $s+S W$, a fraction of the SW's OM is mineralized as it is more labile than that of SVC. The quantity and manner of $\mathrm{CO}_{2}-\mathrm{C}$ production were determined for each sludge and can be attributed to the characteristics resulting from the composting of the raw waste (Tarrasón et al. 2010). Overall, the incorporation of SW provided a pool of easily degradable $\mathrm{C}$ that produces 5 times higher $\mathrm{CO}_{2}-\mathrm{C}$ than that found for $\mathrm{s}+\mathrm{SVC}$. This fact is consistent with the presence of a highly labile DOC associated with the tryptophan-like component (Fig. 5, Ex/Em 280/369) of s + SW which was absent in EEM for s + SVC. The increase in humified, more stable OM in solution for $\mathrm{s}+\mathrm{SVC}$ was revealed by the presence of a distinctive fluorophore at $\mathrm{Ex} / \mathrm{Em}$ $250-340 / 420 \mathrm{~nm}$ in agreement with results presented by Macedo dos Santos et al. (2010). Besides, the pool of small molecular size, more labile compounds observed for $\mathrm{s}+\mathrm{SW}$ was described by those authors. Moreover, these results are agreeable with previous studies (Pedra et al. 2007) on differently textured soils amended with fresh and composted sludge.

Otherwise, qM after addition of SW is described by a more complex model including the synergic effect of $D$ and $t$ (Fig. 1d). In $\mathrm{s}+\mathrm{SCV}$, the highest rate is reached with $<30 \mathrm{~g} \mathrm{~kg}^{-1}$ doses, and $\mathrm{SW}$ with doses around $50-80 \mathrm{~g} \mathrm{~kg}^{-1}$. Higher $\mathrm{qM}$ values obtained for $\mathrm{s}+\mathrm{SW}$ suggested that microbial decomposition of OM was higher compared to $\mathrm{s}+\mathrm{SVC}$. Similar values of HIX were obtained for the application of SW and SVC, with lower HIX values obtained for increasing doses of amendment (Fig. 5). Accordingly, Macedo dos Santos et al. (2010) described a decrease in HIX for the addition of sewage sludge. Although fluorescence spectra collected in Fig. 4 indicate higher presence of humified material in solution for SVC compared to SW, the elevated concentration of fresh material for the application of both amendments in soil hampers the estimation of significant differences between both amendments.

Furthermore, the mixing of SW with mining soil led to a rapid mineralization (a mean of 0.47 days $^{-1}$ ), whereas the mineralization rate of $\mathrm{s}+\mathrm{SVC}$ was lower (a mean of 0.66 days $\left.^{-1}\right)$. The initial potential rate of $\mathrm{C}$ mineralization normalized to total $\mathrm{C}$ showed that $\mathrm{SW}$ provide higher metabolized organic carbon fraction than SVC (Fig. 2).

The RSM model fitted can be optimized for a number of goals in order to contribute to formulate adequate decisions on sludge management practices. Thus, the goals that may apply either to factor $D$ or $t$ are as follows: a target value, or set an exact value. For example, if the dose of SVC should be constrained to $40 \mathrm{~g} \mathrm{~kg}^{-1}$, a maximum $\mathrm{C}_{\min }\left(650 \mathrm{CO}_{2}-\mathrm{C}\right.$ $\mathrm{mg} \mathrm{kg}^{-1}$ ) is reached after 26 days; for the same $\mathrm{SW}$ dose and incubation time, about 5 times more of $\mathrm{CO}_{2}$ is released. As observed, addition of SVC to soil reduced $\mathrm{CO}_{2}$ emissions and increased soil $\mathrm{C}$ sequestration efficiency. At the same time, $\mathrm{C}$ mineralization rates would be the goals for sludge management decision. Then, possible goals related to mineralization rates are as follows: maximize, minimize, or reach a target value. Prediction outcomes as examples are as follows: Maximum $\mathrm{C}_{\min }\left(1,367 \mathrm{CO}_{2}-\mathrm{C} \mathrm{mg} \mathrm{kg}{ }^{-1}\right)$ can be reached after adding $100 \mathrm{~g} \mathrm{~kg}^{-1}$ of $\mathrm{SVC}$ and 30 days incubation; the same $C_{\min }$ value is obtained with $14 \mathrm{~g} \mathrm{~kg}^{-1}$ of SW after 25 days of incubation. 
Table 3 Biochemical properties and incubation data of amended mine dump after incubation step

\begin{tabular}{|c|c|c|c|c|c|c|c|c|c|c|c|}
\hline $\begin{array}{l}\text { Dose } \\
\mathrm{mg} \\
\mathrm{kg}^{-1}\end{array}$ & Waste & $\mathrm{pH}$ & $\begin{array}{l}\mathrm{EC} \mathrm{dS} \\
\mathrm{m}^{-1}\end{array}$ & $\begin{array}{l}\mathrm{OC} \\
\mathrm{g} \mathrm{kg}^{-1}\end{array}$ & $\begin{array}{l}\beta \text {-glucosidase } \\
\mu \mathrm{g} \text { PNP } \mathrm{g}^{-1} \mathrm{~h}^{-1}\end{array}$ & $\begin{array}{l}\text { SBR } \\
\mathrm{g} \mathrm{CO}_{2} \\
\mathrm{~kg}^{-1}\end{array}$ & $\begin{array}{l}\mathrm{C}_{\min } \\
\mathrm{g} \mathrm{kg}^{-1}\end{array}$ & $\mathrm{C}_{\text {biom }} \mathrm{g} \mathrm{kg}^{-1}$ & $\begin{array}{l}\text { Microbial } \\
\text { quotient } \\
\%\end{array}$ & $\begin{array}{l}\mathrm{qCO}_{2} \\
\mathrm{~d}^{-1}\end{array}$ & $\mathrm{qM} \%$ \\
\hline 0 & SW & $8.4(0.2)$ & $0.32(0.03)$ & 1.8 & $2.9(0.3)$ & 0.31 & $0.13(0.02)$ & $0.035(0.008)$ & 1.94 & 0.13 & 7.7 \\
\hline 33 & SW & $8.2(0.2)$ & $1.1(0.2)$ & 12.6 & $99(20)$ & 5.2 & $2.6(0.9)$ & $0.16(0.05)$ & 1.30 & 0.53 & 20.6 \\
\hline 50 & SW & $8.1(0.2)$ & $0.99(0.13)$ & 18.0 & $148(1)$ & 9.1 & $3.9(0.2)$ & $0.26(0.08)$ & 1.46 & 0.50 & 21.7 \\
\hline 67 & SW & $8.1(0.2)$ & $1.1(0.25)$ & 23.4 & 199 (10) & 12.7 & $5.0(0.5)$ & $0.23(0.08)$ & 1.00 & 0.72 & 21.5 \\
\hline 100 & SW & $7.9(0.1)$ & $1.6(0.2)$ & 34.2 & $257(9)$ & 20.8 & $7.1(0.5)$ & $0.81(0.07)$ & 2.36 & 0.29 & 20.7 \\
\hline 0 & SVC & $8.4(0.2)$ & $0.32(0.03)$ & 1.8 & $2.9(0.3)$ & 0.31 & $0.13(0.02)$ & $0.035(0.008)$ & 1.94 & 0.13 & 7.7 \\
\hline 33 & SVC & $7.6(0.2)$ & $0.43(0.03)$ & 8.3 & $22(3)$ & 1.1 & $0.53(0.2)$ & $0.15(0.09)$ & 1.80 & 0.12 & 6.5 \\
\hline 50 & SVC & $7.5(0.2)$ & $0.55(0.05)$ & 11.5 & $41(2)$ & 1.9 & $0.86(0.2)$ & $0.16(0.08)$ & 1.41 & 0.18 & 7.5 \\
\hline 67 & SVC & $7.5(0.2)$ & $0.68(0.04)$ & 14.6 & $47(1)$ & 1.9 & $1.0(0.3)$ & $0.19(0.07)$ & 1.32 & 0.18 & 7.0 \\
\hline 100 & SVC & $8.0(0.2)$ & $0.85(0.05)$ & 21.2 & $53(4)$ & 3.4 & $1.4(0.2)$ & $0.54(0.06)$ & 2.54 & 0.09 & 6.5 \\
\hline
\end{tabular}

Values are mean (standard deviation)

Quotients were obtained using the means of the values

$S B R$ soil basal respiration

$\mathrm{C}_{\text {min }}$ : accumulated $\mathrm{CO}_{2}-\mathrm{C}$ emission after 30 days

$\mathrm{C}_{\text {biom: }}$ : microbial biomass $\mathrm{C}$

Microbial quotient: $\mathrm{C}_{\mathrm{biom}}{ }^{*} 100 / \mathrm{OC}$

Metabolic quotient $\left(\mathrm{qCO}_{2}\right)$ : daily $\mathrm{C}_{\min }$ divided by $\mathrm{C}_{\text {biom }}$

Mineralization quotient (qM): $\mathrm{C}_{\mathrm{min}} * 100 / \mathrm{OC}$

Mine soil properties after sludge disposal

Several chemical and biological parameters were considered in order to determine the state and functionality of the amended soil system at the end of the incubation period (Table 3).

The application of air-dried or co-composted sludge did not cause adverse effects on either $\mathrm{pH}$ or EC, which are two of the main chemical properties essential in soil remediation. The SVC slightly increased the average EC of the mine tailing, while SW strongly increased this parameter (up to 5 times), particularly for the $100 \mathrm{~g} \mathrm{~kg}^{-1}$ dose. Salinity was below the values established as detrimental for plant root viability $\left(\mathrm{EC}>4 \mathrm{dS} \mathrm{m}^{-1}\right.$ ). The addition of SW did not alter the soil $\mathrm{pH}(8.4)$, while $\mathrm{SVC}$ resulted in a significant decrease (7.7) that might provide a more physiologically adequate environment for plant growth.

Incubating mine dump with both amendments increased the $\mathrm{C}_{\min }$ (Table 3) in relation to native soil, as it is expected (Calderon et al. 2004), and enhanced biological activity as evidenced by the $C_{\text {biom }}, \mathrm{SBR}$, and $\beta$-glucosidase activity (Table 3 and Fig. 4). Furthermore, these are particularly high at $100 \mathrm{~g} \mathrm{~kg}^{-1}$ of both substrates but higher after addition of dried sludge. The increase in soil $\mathrm{C}_{\text {biom }}$ can be attributed to growth stimulation of both autochthonous microbiota and the microorganisms contained in the sludge (de Nobili et al. 2011; Saviozzi et al. 1993). Similarly, high $\beta$-glucosidase activity provides an early indication of enhanced soil fertility because this enzyme participates in the degradation of $\mathrm{OC}$, as reported previously (Marando et al. 2011).

The response of soil to each sludge addition is strongly related to the mineralization of $\mathrm{OC}$ inputs as confirmed by factor analysis which indicated that $\mathrm{qM}$ and $\mathrm{qCO}_{2}$ discriminate between SW and SVC mineralization (Fig. 4). Thus, SW contributed with less stabilized OC, whereas SVC provided more humified $\mathrm{C}$ that was similar to that of native soil as it was reported (Pérez-Lomas et al. 2010). Our results (Table 3) indicate an enhancement (fourfold) in the metabolic efficiency of microbial biomass resulting from SVC addition. However, the high $\mathrm{qCO}_{2}$ values found in $\mathrm{s}+\mathrm{SW}$ indicate low efficiency of microbial biomass in using up organic $\mathrm{C}$. Therefore, it can be considered that during mineralization of $\mathrm{OM}$ from $\mathrm{SW}$, microbes divert more $\mathrm{C}$ to respiration than to new microbial biomass, causing more $\mathrm{C}$ loss than in SVCamended soils. This is consistent with report from Anderson and Domsch (2010), who found that high $q \mathrm{CO}_{2}$ values reflect younger microbial communities that rapidly turnover of OC. The lower incorporation of the $\mathrm{OM}$ from SW into the microbial biomass can also be due to stress caused by the toxic effect of non-composted sludge (Domene et al. 2007). 
At the end of the experiment, the $q \mathrm{CO}_{2}$ values did fall because the system was reaching a certain degree of equilibrium after the disappearance of the easily biodegradable $\mathrm{C}$ during the first month.

The examination of DOM characteristics by fluorescence spectroscopy has gained increasing attention during the last decades (Bolan et al. 2011), generally for water samples, but more recently also for soil DOM (Borisover et al. 2012; Xue et al. 2012). Currently, luminescence spectroscopy is the only and most relevant methodological approach available to examine the composition of DOM in sludge-amended soils (Macedo dos Santos et al. 2010). The fluorescence spectra provides semiquantitative information of DOM pools of different lability (Zhou et al. 2013) as well as parameters such as humification index, but significant quantitative relations have not been achieved yet.

The spectrofluorometric analysis of DOM from amended and non-amended soils after 30 days of incubation indicated a decrease in HIX consistent with the incorporation of OC of low chemical stability, particularly as such provided with the application of SW, in agreement with recent studies (Macedo dos Santos et al. 2010; Xue et al. 2012). Moreover, a decrease in the freshness index values $(\beta: \alpha)$ indicated higher rates of decomposition, particularly for SW at the highest dose applied. The slight increase in the values of FI determined is related to higher presence of microbial derived DOM, which was also consistent with the differences in mineralization rates.

\section{Conclusion}

Response surface methodology accomplished a high-performance second-order model that allows the effective examination of OC mineralization process in the amended mine dump constituting the first application of RSM for modeling of soil respiration processes. Additionally RSM, based on D-optimal design, required a lower number of soil incubation experiments than the conventional approach and provided additional information, such as the simultaneous influence of incubation time and dose on the response, and the ability to predict dose of sludge and the mineralization time required to achieve target $\mathrm{C}_{\min }$ and, conversely, to predict $\mathrm{C}_{\text {min }}$ under sludge management constrains, i.e., application sludge dose and/or incubation time. Hence, this information can contribute to the development of sludge management plans for restoration approaches of the mine dump studied.

The impact of new sources of OC in the quality of soil DOM pools was evaluated through spectrofluorometric analysis. The composition of soil DOM upon application of the amendments was associated with the characteristics of sludge, dose, and $\mathrm{C}_{\min }$ rates. Although no quantitative relations can be derived yet, the presence of higher humified material in solution, as such provided with SVC, was consistent with lower $\mathrm{C}_{\min }$ rates. Otherwise, application of SW resulted in a new pool of highly labile OC in solution, consistently with higher $\mathrm{C}_{\min }$ rates. Although further research remains necessary, the results obtained shed some light for a better understanding of the complex $\mathrm{C}$ mineralization process in amended soils. The application of both sludges increased soil OC content and the biochemical properties promoting soil functioning. According to the accepted goal of achieving a rapid restoration of organic matter, our results argued that cocomposted sludge seems to be more appropriate due to its higher content of stable $\mathrm{OM}$ with a lower $\mathrm{C}_{\min }$ than the dried one.

Finally, our findings highlight the importance of performing RMS studies, including abiotic factors playing a role in organic matter mineralization, as temperature, UV radiation, and wet-dry cycles in the $\mathrm{C}_{\min }$ model to establish the OM management strategies in restoration of Mediterranean lands.

Acknowledgments The authors wish to acknowledge funding from the Junta de Andalucía through projects P08-RNM3526 and for a PhD fellowship (A. Sevilla-Perea) co-financed with FEDER funds. MCHS thanks the Fulbright program and the Spanish Ministry of Education for a postdoctoral fellowship (FMECD-2010). EMASAGRA and Biomasa del Guadalquivir are thanked for kindly providing dried and co-composted sludge, respectively.

\section{References}

Amani IT, Nosrati M, Mousavi SM, Kermanshahi RK (2011) Study of syntrophic anaerobic digestion of volatile fatty acids using enriched cultures at mesophilic conditions. Int J Environ Sci Tech 8:83-96

Anderson JPE (1982) Soil respiration. In: Page AL, Miller RH, Keeney DR (eds) Methods of soil analysis. Part 2. Soil Science Society of America, Madison, WI, pp 837-871

Anderson TH, Domsch KH (2010) Soil microbial biomass: the ecophysiological approach. Soil Biol Biochem 42:2039-2043

Blázquez G, Calero M, Hernáinz F, Tenorio G, Martín-Lara MA (2011) Batch and continuous packed column studies of chromium (III) biosorption by olive stone. Environ Prog Sustain Energy 30:576-585

Bolan NS, Adriano DC, Kunhikrishnan A, James T, McDowell R, Senesi N (2011) Dissolved organic matter: biogeochemistry, dynamics, and environmental significance in soils. In: Sparks DL (ed) Advances in agronomy, vol 110. Elsevier Academic Press Inc, San Diego, pp 1-75

Borisover M, Lordian A, Levy GJ (2012) Water-extractable soil organic matter characterization by chromophoric indicators: 
effects of soil type and irrigation water quality. Geoderma 179:28-37

Bufflap SE, Allen HE (1995) Comparison of pore-water sampling techniques for trace metals. Water Res 29:2051-2054

Calderon FJ, Mcarty GW, Van Kessel JS, Reeves JB (2004) Carbon and nitrogen dynamics during incubation of manured soil. Soil Sci Soc Am J 68:1592-1599

de Nobili M, Contin M, Mondini C, Brookes PC (2011) Soil microbial biomass is triggered into activity by trace amounts of substrate. Soil Biol Biochem 33:1163-1170

Delgado Moreno L, Peña A, Mingorance MD (2009) Design of experiments in environmental chemistry studies: example of the extraction of triazines from soil after olive cake amendment. J Hazard Mater 162:1121-1128

Domene X, Alcañiz JM, Andrés P (2007) Ecotoxicological assessment of organic wastes using the soil collembolan Folsomia candida. Appl Soil Ecol 35:461-472

ED 86/278/EEC (1986) European Council, Sewage Sludge Directive, http://ec.europa.eu/environment/waste/sludge/index.htm

Eivazi F, Tabatabai MA (1988) Glucosidases and galactosidases in soils. Soil Biol Biochem 20:601-606

Epstein E (2003) Land application of sewage sludge and biosolids. Lewis Publishers, New York

Eriksson L, Johansson E, Wikstrom C (1998) Mixture design-design generation, PLS analysis, and model usage. Chemometr Intell Lab 43:1-24

Fellman JB, Hood E, Spencer RGM (2010) Fluorescence spectroscopy opens new windows into dissolved organic matter dynamics in freshwater ecosystems: a review. Limnol Oceanogr 55:2452-2462

Fernández JM, Plaza C, Hernández D, Polo A (2007) Carbon mineralization in soils amended with thermally-dried and composted sewage sludges. Geoderma 137:497-503

Gillis JD, Price GW (2011) Comparison of a novel model to three conventional models describing carbon mineralization from soil amended with organic residues. Geoderma 160:306-310

Hernández-Soriano MC, Peña A, Mingorance MD (2007) Response surface methodology for the microwave assisted extraction of insecticides from soil samples. Anal Bioanal Chem 389:619-630

Hernández-Soriano MC, Peña A, Mingorance MD (2010) Release of metals from metal-amended soil treated with a sulfosuccinamate surfactant: effects of surfactant concentration, soil/solution ratio, and $\mathrm{pH}$. J Environ Qual 39:1298-1305

Kalali A, Ebadi T, Rabbani A, Sadri Moghaddam S (2011) Response surface methodology approach to the optimization of oil hydrocarbon polluted soil remediation using enhanced soil washing. Int J Environ Sci Tech 8:389-400

Khuri AI, Mukhopadhyay S (2010) Response surface methodology. WIREs Comp Stat 2010(2):128-149

Lundstedt T, Seifert E, Abramo L, Thelin B, Nyström Å, Pettersen J, Bergman R (1998) Experimental design and optimization. Chemometr Intell Lab 42:3-40

Macedo dos Santos L, Marcondes Bastos D, Milori P, Simoes ML, Lopes da Silva WT, Pereira-Filho ER, de Melo WJ, Martin-Neto L (2010) Characterization by fluorescence of organic matter from oxisols under sewage sludge applications. Soil Sci Soc Am J 74:94-104

Marando G, Jimenez P, Hereter A, Julià M, Ginovart M, Bonmati M (2011) Effects of thermally dried and composted sewage sludges on the fertility of residual soils from limestone quarries. Appl Soil Ecol 49:234-241

Mays DA, Sistani KR, Soileau JM (2000) Lime and fertilizer needs for land reclamation. In: Barnhisel RI, Darmody RG, Daniels WL (eds) Reclamation of drastically disturbed lands. American Society of Agronomy, Crop Science Society of America, Soil Science Society of America, Madison, WI, pp 217-240

Miller MP, Simone BE, McKnight DM, Cory RM, Boyer EW (2010) New light on a dark subject: comment. Aquat Sci 72:269-275

Mingorance MD, Barahona E, Fernandez-Galvez J (2007) Guidelines for improving organic carbon recovery by the wet oxidation method. Chemosphere 68:409-413

Mummey DL, Stahl PD, Buyer JS (2001) Microbial biomarkers as an indicator of ecosystem recovery following surface mine reclamation. Appl Soil Ecol 21:251-259

Myers RH, Montgomery DC (2002) Response surface methodology, 2nd edn. Wiley, New York

Pedra F, Polo A, Ribeiro A, Domingues H (2007) Effects of municipal solid waste compost and sewage sludge on mineralization of soil organic matter. Soil Biol Biochem 39:1375-1382

Pérez-Lomas AL, Delgado G, Párraga J, Delgado R, Almendros G, Aranda V (2010) Evolution of organic matter fractions after application of co-compost of sewage sludge with pruning waste to four Mediterranean agricultural soils: a soil microcosm experiment. Waste Manag 30:1957-1965

Roig N, Sierra J, Martíc E, Nadal M, Schuhmachera M, Domingo JL (2012) Long-term amendment of Spanish soils with sewage sludge: effects on soil functioning. Agric Ecosyst Environ 158:41-48

Rovira P, Rovira R (2010) Fitting litter decomposition datasets to mathematical curves: towards a generalised exponential approach. Geoderma 155:329-343

Saviozzi A, Levi-Minzi R, Riffaldi R (1993) Mineralization parameters from organic materials added to soil as a function of their chemical composition. Bioresour Technol 45:131-135

Sheoran V, Sheoran AS, Poonia P (2010) Soil reclamation of abandoned mined land by revegetation: a review. Int $\mathrm{J}$ Soil Sediment Water 3:1-20. http://scholarworks.umass.edu/intljssw/ vol3/iss $2 / 13 /$

Song U, Lee EJ (2010) Environmental and economical assessment of sewage sludge compost application on soil and plants in a landfill. Resour Conserv Recycl 54:1109-1116

Tarrasón D, Ojeda G, Ortiz O, Alcañiz JM (2010) Effects of different types of sludge on soil microbial properties: a field experiment on degraded Mediterranean soils. Pedosphere 20:681-691

Turrión MB, Lafuente F, Mulas R, López O, Ruipérez C, Pando V (2012) Effects on soil organic matter mineralization and microbiological properties of applying compost to burned and unburned soils. J Environ Manag 95:S245-S249

Vance E, Brookes P, Jenkinson D (1987) An extraction method for measuring soil microbial biomass carbon. Soil Biol Biochem 19:703-707

Xue S, Zhao Q, Wei L, Song Y, Tie M (2012) Fluorescence spectroscopic characterization of dissolved organic matter fractions in soils in soil aquifer treatment. Environ Monit Assess 185:4591-4603

Yuste JC, Baldocchi DD, Gershenson A, Goldstein A, Mission L, Wong S (2007) Microbial soil respiration and its dependency on 
carbon inputs, soil temperature and moisture. Glob Change Biol 13:2018-2035

Zhou J, Wang JJ, Baudon A, Chow AT (2013) Improved fluorescence excitation-emission matrix regional integration to quantify spectra for fluorescent dissolved organic matter. J Environ Qual 42:925-930
Zsolnay A, Baigar E, Jimenez M, Steinweg B, Saccomandi F (1999) Differentiating with fluorescence spectroscopy the sources of dissolved organic matter in soils subjected to drying. Chemosphere 38:45-50 